centre, and some computer scientists looked askance at the SDI office's demand for 10 million lines of error-free computer code and hardware capable of $10^{12}$ operations per second - one thousand times faster than anything currently available. Kogut says that many objected to large amounts of public money being spent on a proposal that would not, in their view, survive a normal scientific peer review.

So far, the protest has spread mainly within physics departments, though there are plans to coordinate it so that it reaches as many scientific departments as possible. The SDI office is maintaining an air of sublime indifference, saying that there will always be differences of opinion among experts on a complicated topic. A spokesman said the petition appeared to have had almost no effect on the response to SDI's invitation; more than 3,000 research proposals have already been received.

More than 70 per cent of the $\$ 28$ million budget for the Innovative Science and Technology Office in 1985 has been spent in US universities, and the amount is likely to rise sharply in coming years. The administration's proposed budget for star wars in 1986 is $\$ 3,700$ million, although Congress appears unlikely to grant the full request. The figures currently being discussed range from $\$ 2,700$ million to $\$ 3,000$ million.

Tim Beardsley

\title{
SDI story so far
}

The SDI Innovative Science and Technology Office has so far announced seven "consortia" undertaking SDI research, involving 33 academic institutions (mostly universities), 12 private companies and sundry government laboratories. Following protests from some institutions that their names were being used without permission to lend credibility to the star wars programme, the SDI organization is now careful to say that the consortia are composed of individual scientists rather than institutions.

According to James Ionson, who heads the innovative science office, all basic research conducted on university campuses will remain unclassified. SDI research that does have to be classified is carried out in government laboratories or by private companies. The seven consortia will tackle the following subjects:

\section{Subject}

Amount $(\$$ million,

Non-nuclear space

power (over 4

years) over 3 years)

Composite materials

Optical signal processing

Novel electronic and optical materials

Advanced electronics

Nuclear space power 19

Soviet research

\section{Over-emphasis on production}

DURING the past decade. Soviet science planners have put increasing emphasis on direct research contracts between the production sector and the universities and research institutes of the Academy of Sciences. Such contracts have been viewed not only as a useful source of additional income for the institutes undertaking the research, but also as an important means of mobilizing the university and academy sectors in implementing the gains of the "scientific and technical revolution" in the economy. Indeed, when addressing the special Central Committee meeting on accelerating scientific and technical progress in June, Mr Gorbachev gave strong hints that such contracts would be even more important in the future, while there would be considerable cutbacks in the (often unproductive) network of specialized research institutes belonging to the individual production ministries.

Recently, however, a leading Soviet scholar has suggested that industrial contracts are not, after all, the best way of financing university science. Dr Sergei Ambartsumyan, the rector of Erevan State University, a member of the credit.

\section{Spanish research}

\section{New law to change attitudes?}

\section{Barcelona}

WiTH an eye to the future application of the Law of Science, already presented to the Spanish parliament (Nature 314, 661; $1985)$, a variety of scientific and institutional initiatives recently announced by the Consejo Superior de Investigaciones Cientificas (CSIC) are beginning to be put into practice. According to authorities in the CSIC, which the law says is to undergo "re-foundation", the initiatives are aimed at achieving better coordination between the groups and a more dynamic administration in this institution, which accounts for much of the research done in Spain and 30 per cent of Spanish publications in international journals.

At present, the entire scientific activity of CSIC groups is organized into approximately 250 projects. These projects have been presented for evaluation to the main Spanish granting agency (CAICYT, part of the Ministry of Education and Science) and have been sent to independent referees. Several specific programmes (Programas Movilizadores) have been defined for the encouragement and coordination of research in priority topics of special scientific interest, especially those having social and economic scope. These include programmes on lasers, new materials, toxicology, food technology and natural resources.

In addition there are the thematic programmes. These are intended to establish
Armenian Academy of Science and a Deputy of the Supreme Soviet of the USSR, last month pointed out in Izvestiya that the contract system leads to a shortage of funds for pure research. According to Ambartsumyan, 40 per cent of Soviet scientists work in the university sector, but their research budget amounts to only five to seven per cent of the Soviet total. In order to finance fundamental research, the leading Soviet universities need at least to double their research budget by income from contracts. The production sector, however, is interested only in practical results.

Not only to the universities lack research funds; according to Ambartsumyan they are increasingly unable to attract the talented young scientists needed to carry out the planned research committments.

Shortly before Ambartsumyan's article appeared, new pay-scales for Soviet scientists were, indeed, announced; but these seem designed to reward outstanding achievers, not to help young scientists with as yet no major achievements to their

Vera Rich contacts between groups working in related subjects either in CSIC, universities or other research centres. Several of these programmes have been approved so far, including those in neurosciences, genetic engineering, space sciences, information technology and marine biology.

This may be a new way to improve contacts between CSIC institutes and the universities, traditionally strained because of distrust between Spanish state institutions. In the past two years CSIC has signed agreements with almost all Spanish universities with the intention of creating a framework that might stimulate the collaboration of research groups working in the two environments. CSIC has also revised its own institutes. In the past two years more than 80 institutes, some consisting only of one person, have disappeared, but new centres for biotechnology, for microelectronics and a Centre for Advanced Studies in Blanes, Costa Brava, have been created.

There is a general awareness that these reforms should go hand in hand with an increase in the funds for research and in staff. In fact, the budget of CSIC has been doubled in the past three years, reaching, in $1985,21,000$ million pesetas (US $\$ 120$ million). Moreover, 200 new research positions have been announced recently, in an institution employing 1,250 scientists, and a similar number will be added next year.
Pedro Puigdoménech 